\title{
Contrastes e confrontos na obra de Guimarães Rosa
}

Luiz Cláudio Vieira de Oliveira I FUMEC

\begin{abstract}
Resumo: A obra de Guimarães Rosa evidencia, de Magma a Tutaméia, um percurso em que o autor opta pelo trabalbo metalingüistico com o texto, executando uma renovação lingüistica e narrativa na ficção brasileira. Esta opção revela que o autor não teve ou desejou uma atuação política, nem procurou fazer uma literatura revolucionária, engajada, preocupando-se antes em realizar uma transformação na literatura. As análises que buscam tal literatura revolucionária na obra rosiana desconbecem a opção estética do escritor.

Palavras-chave: opção estética, opção ideológica, metalinguagem.
\end{abstract}

Guimarães Rosa não surgiu do nada. Veio de Cordisburgo para Belo Horizonte, daí para Itaguara, de lá para Barbacena, depois para o Rio e, finalmente, para o mundo. O lugar de onde fala é constituído por todos esses lugares, contaminando-se a sua dicção dos muitos falares com que teve contacto. O sertão é o mundo, nos diria Riobaldo.

$\mathrm{Na}$ literatura brasileira, Guimarães Rosa se insere numa vereda que se inicia ainda no século XIX, com o Romantismo, e se prolonga pelo século XX. Dela participam autores tão diferentes, e com projetos estéticos e ideológicos tão díspares quanto Amadeu Amaral, Cornélio Pires, Hugo de Carvalho Ramos, Valdomiro Silveira, Simões Lopes Neto, Domingos Olímpio, Afonso 
Arinos, José Lins do Rego, Graciliano Ramos, autores que tiveram ampla repercussão à época, constituindo-se como leitura obrigatória à época em que Rosa se preparava para ser um autor. Até 1943, ano de lançamento de Fogo Morto, três anos antes de Sagarana, José Lins do Rego já havia publicado sua obra ficcional mais significativa. Até 1945, Graciliano Ramos também já publicara a maioria de seus livros, entre os quais Caetés, Angústia, São Bernardo e Infância. Memórias do cárcere é de 1951. Os dois escritores já se haviam firmado como grandes autores à época, e muito possivelmente foram lidos por Guimarães Rosa.

Não se deve buscar, nesses antecedentes, próximos ou remotos, uma proposta ou um projeto literário unificado. Antes, devem ser tomados como autores que se ocuparam de uma parcela característica da realidade brasileira, o que os torna partícipes do que se convencionou chamar de regionalismo, com todos os defeitos e acertos de um rótulo. A esse respeito é interessante consultar "O modernismo na ficção", especialmente as partes que cabem a Afrânio Coutinho - "Antecedentes" - e a Costa Lima "Regionalismo", ambas de A literatura no Brasil. Rosa integra-se a essa tradição e, num primeiro momento, é como regionalista que será tomado pela crítica. É também interessante reproduzir as palavras de Ettore Finazzi-Agrò:

Voltando, nesse sentido, mergulhando-nos numa geografia e numa história virtuais, anteriores (e/ou posteriores) a qualquer história e a qualquer geografia, Guimarães Rosa nos arrasta muito além (e/ou nos leva aquém) do regionalismo, fazendo-nos intuir a razão histórica implícita na divisão regional [...] a superficialidade daquilo que se considera "região", recaímos num espaço sem trânsito - numa "aporia" [..... ${ }^{2}$

Além dos autores citados como precursores de Rosa, como ficcionistas ou como intelectuais, construtores de uma visão moderna sobre o Brasil, deve-se mencionar Euclides da Cunha, Sérgio Buarque de Holanda, Caio Prado Jr., Lima Barreto, Monteiro Lobato, Mário de Andrade e, dentro de uma proposta mais radical, Oswald de Andrade. Mesmo que Guimarães Rosa não os tenha lido a todos, sua curiosidade intelectual o teria levado a situar-

1. Veja-se também "Jagunços mineiros de Cláudio a Guimarães Rosa", de Antonio Candido.

2. FINAZZI-AGRÒ, 2001, p. 87. 
se dentro de um espírito modernista e reformista presente no Brasil a partir da virada do século, com momentos bem marcados nos anos vinte e trinta.

Por outro lado, Guimarães Rosa herdou, trazida por diferente vereda, uma consciência metalingüística e um trabalho sofisticado com a linguagem, já presentes em Machado de Assis, e que se pode perceber também em Graciliano Ramos e em Mário de Andrade. Portanto, seu regionalismo não é "só" regionalismo, no sentido mais simplista e redutor do termo. Sua literatura se aproxima mais da que foi produzida por esses três últimos autores do que, por exemplo, do anedotário caipira de Cornélio Pires ou do caráter folclórico, que há na obra de Valdomiro Silveira, ou etnográfico, da obra de Amadeu Amaral. Além disso, o texto rosiano, de Sagarana a Grande Sertão: Veredas, passando por Corpo de Baile, terá uma qualidade e uma densidade que nos farão lembrar Machado, Mário e Graciliano. É a consciência metalingüística de Rosa que o fará transcender o regionalismo, alçando-se a vôos mais altos em relação ao uso da linguagem e ao desenvolvimento de técnicas narrativas mais apuradas, que o levarão aos contos e à metalinguagem dos prefácios de Tutaméia.

João Luiz Lafetá, no artigo "Estética e ideologia: o modernismo em 1930", defende a existência de dois momentos de nosso Modernismo: o projeto estético, característico do espírito da Semana de 22; e o projeto ideológico, marca inconfundível do chamado "romance de 30". De acordo com as palavras de Lafetá, para podermos considerar qualquer movimento literário como renovador, é preciso situá-lo em relação à série literária e em relação às séries sociais:

Decorre daí que qualquer nova proposição estética deverá ser encarada em suas duas faces (complementares e, aliás, intimamente conjugadas; não obstante, às vezes relacionadas em forte tensão: enquanto projeto estético, diretamente ligadas às modificações operadas na linguagem, e enquanto projeto ideológico, diretamente atada ao pensamento (visão de mundo) de sua época. ${ }^{3}$

Os dois projetos não são excludentes, mas conjugados e relacionados, como diz o autor, que assim se refere à primeira fase do modernismo brasileiro: "A convergência de projeto estético e de projeto ideológico deu as obras mais radicais, mais tipicamente modernistas [...]: o Miramar e o Serafim, de Oswald de Andrade, o Macunaíma de Mário, a contundência estética da

3. LAFETÁ, [1972?], p. 19. 
poesia Pau-Brasil." ${ }^{4}$ Podemos dizer que Guimarães Rosa compartilha desse mesmo espírito, o que o levou a produzir uma obra também radical. Mas em relação ao projeto ideológico dos anos 30, que procurava, ainda segundo Lafetá, "[...] reformar ou revolucionar essa realidade", não se pode dizer que Rosa compartilhava desse ideário. Entre Sagarana e Grande Sertão: Veredas, há diferenças na recepção crítica da obra rosiana. Sagarana foi saudado como um bom livro regionalista, porque se enquadrava nos padrões de recepção dos leitores da época, vindos também da mesma tradição literária que Rosa. Grande Sertão: Veredas foi recepcionado como algo denso e desconhecido. Hermético e impenetrável para aqueles que o recusaram de imediato; difícil, mas promissor, que o reconheceram como uma obra prima. Antonio Candido, no início de "O homem dos avessos", nos diz:

"Na extraordinária obra-prima Grande Sertão: Veredas há de tudo para quem souber ler, e nela tudo é forte, belo, impecavelmente realizado. Cada um poderá abordá-la a seu gosto, conforme o seu ofício: mas em cada aspecto aparecera o traço fundamental do autor: a absoluta confiança na liberdade de inventar."

Essas palavras, repetidas à exaustão pela crítica, devem ser consideradas por um duplo aspecto. Primeiro, reconhecem a opção estética feita por Rosa, a "absoluta confiança na liberdade de inventar"; segundo, tornaram-se um aval para que tudo pudesse ser descoberto no romance: do esoterismo à sociologia, da história à cultura popular, da linguagem à filosofia. Mas, como bem observou Antonio Candido, com agudeza, "há de tudo para quem souber ler". Nem toda interpretação é possível: há que haver um limite para o desvario, as associações paradigmáticas mais inesperadas e irracionais, como a de identificar Seo Ornelas com Getúlio Dorneles Vargas; ou relacionar um velho a Antônio Conselheiro, apenas porque dava conselhos. ${ }^{7}$ Em

4. LAFETÁ, [1972?], p. 23.

5. LAFETÁ, [1972?], p. 27.

6. CÂNDIDO, 1978, p. 121.

7. RONCARI, Luiz. Participação em Mesa Redonda "A letra e a voz em Guimarães Rosa”, do Seminário Internacional 50 anos de Grande Sertão: Veredas, de João Guimarães Rosa. Belo Horizonte, 23 de maio de 2006. 
Metafísica do Grande Sertão, de Francis Utéza, encontra-se uma outra interpretação para o nome e, daí, para a função de Seo Ornelas, em que as significações são um tanto forçadas. Veja-se:

O senhor da Barbaranha presta imediatamente as honras de sua residência ao chefe jagunço, recebendo-o à mesa como a um hóspede de valor. Tal cortesia, por mais que a julguemos do exterior, não parece ditada pelo temor. Josafá Jumiro Ornelas é um príncipe de alta linhagem e Riobaldo reconhece esta supremacia desde o primeiro contato: aprecei a soberania dele, os cabelos brancos, os modos calmos. Bom homem, abalável. Por êle, por nobreza, tirei meu chapéu [p. 342]. [...] O nome desse representante da tradição - Homem dos sertões transatos - traz o cunho dessa mesma sabedoria: Josafá - o Yabvé julgou -, nome de um rei bíblico de Judá, artesão da paz entre seu próprio reino, no sul, e o reino do norte, Israel; Jumiro, do latim jus: a justiça, e do germânico Mir, Mêrs: conhecido. Príncipe da justiça, isto é, do equilíbrio, da harmonia, do justo termo, da quintessência, ele pertence ao império do Céu. Em Ornelas encontra-se ornis: ave (grifos do autor).

Discordamos também de Willi Bolle, quando defende que "é a questão do pacto com o Diabo que fundamenta a narração de Riobaldo", e em seguida reitere: "Minha tese é que o pacto em Grande Sertão: Veredas pode ser entendido como uma visão romanceada daquilo que a filosofia política, no limiar da modernidade, imaginou como sendo a base da sociedade civil e do Estado." Esta tese, Bolle retoma em seu livro grande sertão.br, em que diz: "No episódio do pacto estão centrados todos os demais acontecimentos do romance. É o Diabo que garante a manutenção da guerra - o estado de exceção, em que são suspensas as leis vigentes e forjadas leis novas pelo mais forte." ${ }^{10}$ Em primeiro lugar, é preciso dizer que não há pacto, não há demônio: o que há é o homem humano em sua travessia. Atribuir ao pacto a base da narração de Riobaldo é desconhecer, primeiro, a estrutura do romance como um todo, dimensionando excessivamente um episódio; segundo, acreditar nas palavras de Riobaldo de que o pacto efetivamente se deu quando, pela própria narração, há apenas um desafio e, pela ausência de

8. UTÈZA, 1994, p. 145.

9. BOLLE, 1997/1998, p. 30-35.

10. BOLLE, 2004, p. 151. 
resposta, a conclusão de que o desafiante, Riobaldo, saiu vencedor. É um processo semelhante ao da personagem do conto de Primeiras estórias, para quem o fato de o jacaré não ser visto não significa que não exista um jacaré ali. “ - 'Você já viu jacaré lá?' - caçoava Pele. - 'Não. Mas você também nunca viu o jacaré-não-estar-lá. Você vê é a ilha, só. Então, o jacaré pode estar ou não estar..." " Finalmente, dar ao episódio do pacto a característica de ser a base da sociedade civil e do Estado é também não querer ver que o "Estado" de Riobaldo se circunscreve aos limites de sua propriedade e aos da sua vizinhança, devidamente guardadas por seus jagunços. Deve-se, por princípio, desconfiar das palavras do narrador, especialmente se for alguém como Riobaldo, cujos motivos para iniciar a narração não são claros. É preciso considerar o texto, mas sempre procurando ler o que há sob ele.

A narrativa de Riobaldo se fundamenta num processo argumentativo, que convoca causas para explicar uma conseqüência, num nítido processo teleológico. São as conseqüências - a morte de Diadorim e os efeitos dessa morte - que criam uma demanda para as causas. Mais que isso, a morte de Diadorim revela que o jagunço é, na verdade, Maria Deodorina da Fé Bettancourt Marins: "[...] que nasceu para o dever de guerrear e nunca ter mêdo, e mais para muito amar, sem gôzo de amor... Reze o senhor por essa minha alma." "É a morte de Diadorim, e as conseqüências que provoca, positivas e negativas, que geram em Riobaldo um terrível remorso, o seu "temer de consciência", e a necessidade de explicar, para si, para o interlocutor, e para todos nós, todos os fatores aleatórios que fizeram com que os fatos se encadeassem de determinada maneira e não de outra.

A argumentação de Riobaldo pretende afastar de si mesmo a responsabilidade pelos atos cometidos, que culminaram com a morte de Diadorim e com a chegada ao poder. Ao mesmo tempo, pretende atribuir tal responsabilidade a alguma provável causa: o destino, o demônio, a maldade humana, a expiação de pecados cometidos em outra vida. Tais causas são, na verdade, argumentos com que se defende e constrói, para si e para os outros, uma imagem em que se esforça por acreditar, ainda que saiba que o que há, mesmo, é o "homem humano".

11. ROSA, 1967, p. 119.

11. ROSA, 1970, p. 458. 
Nada disso, entretanto, tira o brilho ou o mérito do romance como uma sofisticadíssima construção ficcional, nem empana a profundidade com que Rosa soube revestir as reflexões do personagem, atingindo níveis comparáveis às melhores obras da literatura mundial. As dúvidas existenciais e metafísicas de Riobaldo são as nossas dúvidas, as de qualquer ser humano que, para não se deparar consigo mesmo, tenta construir uma imagem, uma identidade em que possa se reconhecer, acreditar e "aplacar o seu temer de consciência".

A crítica sociológica de Antonio Candido foi importante para revelar que o sertão da obra não constituía uma realidade apenas mítica, mas real, física e social, e que os personagens que se moviam na ficção eram próximos de outros, também reais, existentes nas sesmarias e fazendas do sertão de Minas. Mas Antonio Candido ultrapassa o sociológico para tocar o simbólico: apesar do lastro físico e social, Grande Sertão: Veredas tem um arcabouço simbólico alicerçado no sertão, mas que o transcende. Nessa análise, nesse salto qualitativo do sociológico para o simbólico, o crítico paulista cunhou uma frase que é, a meu ver, a mais importante de seu ensaio, dando oportunidade para que outras leituras enveredassem pelo que ela traduz: "Riobaldo somos nós". Nós nos identificamos plenamente com ele.

Essa é a grande descoberta sobre a obra: a profunda humanidade de um personagem, captado com toda a sua contradição, seus desejos, seus anseios, suas frustrações e suas lutas. É isso que rendeu a Riobaldo sua permanência na galeria dos maiores personagens da literatura mundial, ao lado de Dom Quijote, de Fausto, de Ulisses, do Lazarillo, de Raskolnikoff, de Bentinho, todos eles conscientes, em algum momento, de que eram seres muito provisórios. Todos eles têm grandeza e miséria, passando de um estado a outro e nos deixando, a nós, leitores, conscientes de também somos um misto de grandeza e miséria, pólos entre os quais oscilamos.

Riobaldo, personagem e narrador, conduz sua narrativa de acordo com a complexidade que lhe confere essa humanidade. Não tem como objetivo expor uma situação, explicá-la didaticamente, como faria um professor a seus alunos, esclarecê-la. Os limites de sua explicação coincidem com a imagem que constrói, para si e para os demais. Essa imagem é positiva: Riobaldo não se apresenta como vilão, encarnando o mal, mas como uma positividade. Sua imagem é a imagem que interessa, e não a que traduz a verdade, uma verdade, qualquer que seja. Lembrando a tragédia de Sófocles, Édipo-Rei, devemos 
recordar que Édipo, conduzindo seu inquérito, pretendia chegar a uma verdade, mas não necessariamente à verdade a que levaram suas averiguações. Vítima de suas testemunhas, caiu por causa dos testemunhos, irrefutáveis, que se foram somando e esclarecendo tudo. Édipo foi obrigado a ver. Como nos diz Foucault:

Se Édipo cai em uma armadilha, é precisamente porque, em sua vontade de encontrar, ele prolongou o testemunho, a lembrança, a procura das pessoas que viram até o momento em que foi desenterrado do fundo do Citerão o escravo que havia assistido a tudo e que sabia a verdade. O saber de Édipo é esta espécie de saber de experiência. É ao mesmo tempo este saber solitário, de conhecimento, do homem que, sozinho, sem se apoiar no que se diz, sem ouvir ninguém, quer ver com seus próprios olhos. ${ }^{13}$

Riobaldo, não. Como o único depoimento sobre ele, a que temos acesso, é o seu, somos obrigados a ver exclusivamente o que nos conta. Essa parcialidade é favorável ao personagem, cujo interesse em chegar à verdade está submetido à necessidade de que essa verdade não o obrigue a cegar-se, como Édipo, nem a perder o poder, como também acontece com o herói grego. Essa dimensão humana, sectária, parcial e tendenciosa é que dá a Riobaldo a sua humanidade, sua grandeza e sua baixeza. É isso que o torna interessante e atraente para o leitor, que sempre volta a Grande Sertão: Veredas.

O que é Grande Sertão: Veredas? Nada mais, nada menos que uma estória de amor, com a diferença (enorme) de que se trata de um amor entre dois homens, passada no sertão, na primeira metade do século XX. Uma estória de amor temperada por altas doses de erotismo, sempre crescente, com a consciência de Riobaldo de que é um amor homossexual e impossível. Portanto, há duas constatações: de que é um amor profundo e de que é impossível. Isso leva o personagem a uma decisão difícil, porém radical: na impossibilidade desse amor, deixa que o amante morra. A solução final é prática e não compromete o narrador, cuja omissão fica resguardada por um desmaio, real ou falso, durante a batalha final, no Tamanduá-tão.

Mas o que parecia ser a solução de todos os problemas, passa a ser um problema, pois gera a angústia do narrador, o seu remorso e, num determinado momento, sua narrativa. Diadorim morta se revela como mulher,

13. FOUCAULT, 1996, p. 47. 
deixando evidente que sua sexualidade não era um obstáculo, mas um favorecimento ao amor. Mas Riobaldo, na sua humanidade, havia eliminado o homem que era Diadorim, e o rival que Diadorim constituía, porque herdeiro real do poder no sertão. Riobaldo tem consciência de que deixou Diadorim morrer: por isso a angústia, o remorso, a narrativa.

Humanamente, Riobaldo conta sua estória com dois objetivos: primeiramente, compreender porque fez o que fez, convencendo-se de uma verdade; em seguida, convencer o interlocutor, fazendo-o crer nessa verdade. Assim, o personagem atribui suas ações a duas causas: o destino e o demônio. Ao mesmo tempo, caracteriza-se como vítima, levado de roldão pelos acontecimentos, que não domina. Riobaldo nos conta sua estória como uma versão dos fatos que, como sabemos, têm várias versões. Ao eleger a sua como única, dá-lhe o caráter de Verdade, com maiúscula, como se fosse realmente a única.

Se se convence, não sabemos. Parece que sim. Tudo indica que tenha conseguido convencer seu interlocutor, que se prestou a transcrever seu discurso. E, ao que parece, segue nos convencendo, a nós, leitores e críticos, que sempre retomamos Grande Sertão: Veredas, seduzidos pela humanidade do narrador, exatamente porque, na sua fusão de contrários, na sua instabilidade, ela não nos permite uma conclusão definitiva. Como não consente que se conclua que Riobaldo erigiu sua verdade, já que o romance termina com o destaque da humanidade e da ambigüidade do personagem: "O que existe é homem humano. Travessia.".

É ao longo desse fio condutor - amor, poder e remorso - que se deve construir a leitura de Grande Sertão: Veredas, que permite múltiplas interpretações, mas não admite todas elas. Portanto, ainda que queiramos lêlo de acordo com nosso gosto e nosso ofício, conforme a recomendação de Antonio Candido, é necessário que partamos do romance, de suas informações, concordando com elas ou não, confiando e desconfiando do saber e da sabedoria do narrador que, lembremos, não é dono da Verdade que se esforça por construir, mas possuidor de uma versão dos fatos que ocorreram.

As referências que, no romance, se fazem à República, ao "nacional", aos políticos mandatários, à Coluna Prestes, às cartas "do tempo do Imperador", têm que ser lidas como uma ambientação criada para o romance, como um cenário que dá verossimilhança ao texto, e não como uma consciência política, reformista, que proponha um novo modelo de 
nação. Como diz Riobaldo para seu interlocutor: "O senhor deve de ficar prevenido: esse povo diverte por demais com a baboseira, dum traque de jumento formam tufão de ventania. Por gôsto de rebuliço. Querem-porquequerem inventar maravilhas glorionhas, depois êles mesmos acabam temendo e crendo." ${ }^{14}$ Lembrem-se as palavras de Rosa a Günther Lorenz, por ocasião do Congresso de Escritores Latino-Americanos:

Embora eu veja o escritor como um homem que assume uma grande responsabilidade, creio entretanto que não deveria se ocupar de política; não desta forma de política. Sua missão é muito mais importante: éo próprio homem. Por isso a política nos toma um tempo muito valioso. Quando os escritores levam a sério o seu compromisso, a política se torna supérflua. Além disso, eu sou escritor, e se você quiser, também diplomata; politico nunca fui (Grifo nosso).

Guimarães Rosa não se assume como político, mas como escritor. Como enfatiza, sua missão, como escritor, é "o próprio homem". E disso dá conta, perfeitamente bem, em sua obra, especialmente em Grande Sertão: Veredas, ao demonstrar a profunda humanidade de Riobaldo, da mesma forma que Macunaíma e Bentinho, para citar apenas dois dos maiores personagens de nossa literatura, são grandes porque são humanos, falhos, contraditórios, capazes de gestos excelsos e de baixezas.

Teria sido fácil, para Rosa, levantar uma bandeira política, qualquer que seja. Teria sido fácil para ele indicar em que veredas de sua obra tais manifestações de consciência política seriam encontradas, tal como fez quando informou sobre o significado de Moimeichego ou que a exclamação "Aí, Zé, opa" deveria ser lida como "A poesia". Ou mesmo quando esclarece sobre os nomes dos personagens, fazendeiros e enxadeiros, do conto "Cara-de-Bronze" Não há, em sua obra, a contundência de Oswald ou a consciência ideológica de Graciliano. Indiretamente, apenas, é que se pode falar num projeto ou intervenção ideológica de Rosa como, por exemplo, se observa em "A hora e vez de Augusto Matraga", na análise de Milton José Pinto, que destaca a passagem, de Matraga, a pólos opostos da organização social e política do sertão: da cultura política - em que valores como agressividade e sexualidade

14. ROSA, 1970 , p. 59.

15. LORENZ, 1983, p. 62-63. 
desregrada são sintetizados pelo termo homência - à cultura sexual, em que os valores passam a ser os da família (religiosidade) e os da sexualidade controlada para a reprodução. ${ }^{16}$

Em Grande Sertão: Veredas não há também um projeto ideológico, no mesmo sentido que Lafetá o emprega para caracterizar a literatura de 30. Há episódios, isolados no conjunto do romance, que podem ser analisados como instantes de consciência política do autor: a ambição política de Zé Bebelo, que intenta reformar o sertão, e episódio dos catrumanos, perdidos nos confins do sertão, a intromissão de uma política externa, feita pelos coronéis, no dia-a-dia sertanejo, sobejamente analisada por Walnice Galvão, em As formas do falso, pelo próprio Antonio Candido, no capítulo "Jagunços mineiros de Cláudio a Guimarães Rosa", ou por Vera Andrade, em "Conceituação de jagunço e jagunçagem em Grande Sertão: Veredas". ${ }^{18}$

Portanto, achamos que não procede a afirmação de que o romance seja

[...] uma espécie de síntese do universo ficcional de Guimarães Rosa e de seu projeto literário: a surda tentativa de iluminar uma visão do Brasil e convertê-la em palavras. De maneira muito própria, o romance deixa entrever uma ambição fundadora, recriando literariamente as tentativas de transformação de uma comunidade territorial, lingüística, étnica ou religiosa numa forma de vida política duradoura, por meio da contemplação espantada de um mundo arcaico, longínquo, fechado sobre si mesmo, supostamente imóvel e mítico - o Sertão. ${ }^{19}$

Acreditamos que Rosa tivesse um projeto literário, especialmente dirigido para uma nova forma de pensar a línguagem e a narrativa, e é aí que está a sua radicalidade, aproximando-o de Oswald de Andrade. Esse projeto está claro desde Sagarana, concretizado em "São Marcos" e outros contos. No entanto, não cremos que tivesse um projeto político. Seu projeto literário, estético, é bem evidente, como se vê nas orelhas de Grande Sertão: Veredas e de Primeiras estórias, nos prefácios de Tutaméia, na construção minimalista

16. PINTO, 1973, p. 39-48.

17. GALVÃO, 1972.

18. ANDRADE, 1983.

19. STARLING, 1999, p. 13. 
de Primeiras estórias e de Tutaméia, nas múltiplas estórias entremeadas em narrativas maiores, como formas abismáticas de recontar versões da narrativa principal, como em "Dão-la-la-lão", "Recado do morro" e o próprio Grande Sertão: Veredas, com as estórias de Maria Mutema, Pedro Pindó, Aleixo e outras.

Não se pode ler a obra de Guimarães Rosa em fragmentos. Sua obra forma um conjunto, de modo que uma obra conduz à outra, fornecendo chaves de leitura. Magma, seu livro de estréia, dissemina-se em outros textos, uma vez que fragmentos dos poemas são utilizados em textos posteriores.

\begin{abstract}
Além do que indicamos, outras aproximações entre os textos de Magma e os de outros livros de Guimarães Rosa poderão ser estabelecidas. Nossa intenção foi a de mostrar aquelas semelhanças mais diretas, que podem ser percebidas a olho nu, reservando-nos o direito, em futura pesquisa, de ir mais a fundo nesse trabalho de arqueologia literária ou de crítica genética. Buscamos as ressonâncias de Magma na obra futura de Guimarães Rosa, presença que burlou sua consciência criadora. Apesar de seu desinteresse em publicá-la em vida e malgrado tê-la esquecido ao recordar a origem de Sagarana, Magma persistiu como um lastro subterrâneo em toda a sua obra. Tentamos, e parece-nos que conseguimos, mostrar que o contista de Tutaméia já estava dentro do poeta de Magma, como a fruta dentro da casca e que, admirando um, naturalmente chegaremos a admirar e amar o outro. Unir as duas pontas da obra de Guimarães Rosa será sempre tarefa difícil, uma vez que por baixo de cada texto haverá uma camada instável e fugidia, desconhecida e inacessível, mas que às vezes aflora à superfície e se cristaliza, como um magma.
\end{abstract}

Guimarães Rosa executa um percurso que vai de um tipo de literatura minimalista, como a poesia de Magma, passando pelos contos de Sagarana, que não fogem muito do perfil tradicional, na temática ou no tamanho, pelas narrativas longas de Corpo de Baile, cujos contos são enormes, chegando a Grande Sertão: Veredas e, novamente, assumindo uma narrativa minimalista em Tutaméia e em Primeiras estórias, fechando o ciclo, impondo uma circularidade a sua obra: do minimalismo ao minimalismo. Não que isso tenha sido deixado de lado nas narrativas longas. Ao contrário, cada narrativa é um conjunto de detalhes sofisticados, muitas vezes difíceis de serem percebidos, outras vezes indicados e explicados pacientemente pelo autor.

20. OLIVEIRA, 2000, p. 125. 
Rosa executa um projeto literário claro e consciente. Sua obra não cresceu ao sabor do momento. Ela foi pensada como um todo e deve ser lida como um todo.

É sintomático que alguns dos melhores trabalhos críticos sobre a obra rosiana tenham sido feitos por poetas concretistas, como Haroldo de Campos, Augusto de Campos e Pedro Xisto, que souberam perceber o trabalho de Rosa com o significante, a preocupação com o detalhe, a presença da poesia misturada à sua prosa, a consciência metalingüística. O momento em que Rosa começa a publicar é também o instante em que a poesia concreta começa a surgir e se ideais de poesia se difundem. É bem possível que, como partícipes da mesma formação discursiva, no sentido que Foucault dá ao conceito, concretistas e Rosa tenham convergido para um tipo de literatura mais voltado para o significante e mais preocupado com pesquisas formais. Nesse sentido os concretistas ultrapassam a abordagem feita por Osvaldino Marques, que valorizou mais o aspecto puramente lexicográfico da obra rosiana, numa abordagem inserida nos estudos lingüísticos da época.

Portanto, à maneira de Xavier de Maistre, Guimarães Rosa empreende uma "viagem à volta do meu sertão", como Riobaldo realiza uma outra viagem "à volta de si mesmo". É aí que devemos buscar as respostas para as questões que personagem e autor nos colocam. Mas devemos fazer isso com olhos para o que a obra de um e o relato de outro nos podem oferecer. Mesmo que saibamos que toda leitura é o entrecruzamento de dois textos diversos: o que estamos lendo e o que mobilizamos para ler o primeiro, é preciso cuidado para que o nosso não se sobreponha ao de Rosa e para que não vejamos, em sua obra, apenas aquilo que estivermos interessados em ler.

Résumé: L'oeuvre de Guimarães Rosa rend évident, dès Magma jusqu'à Tutaméia, un choix de l'auteur pour le travail metalinguistique avec le texte, où il réalise une renovation linguistique et narrative dans la fiction brésilienne. Ce choix montre que l'auteur n'a pas eu ou n'a pas voulu une action politique, ou qu'il a fait une littérature révolutionnaire, engagée. Il avait une préocupation de transformer la littérature. Les analyses qui cherchent telle littérature révolutionnaire dans l'oeuvre de Guimarães Rosa ne connaissent pas l'option esthétique de l'auteur.

Mots clés: choix esthétique; choix idéologique; métalangage. 
ANDRADE, Vera. Conceituação de jagunço e jagunçagem em Grande Sertão: Veredas. In: In: COUTINHO, Eduardo F. Guimarães Rosa. Rio: Civilização Brasileira; Brasília, INL, 1983. p. 491-499. (Coleção Fortuna Crítica, 6).

BOLLE, Willi. O pacto no Grande Sertão - esoterismo ou lei fundadora? Revista USP: Dossiê 30 anos sem Guimarães Rosa, São Paulo, n. 36, p. 26-45, dez./fev. 1997/1998.

BOLLE, Willi. Grande sertão.br. São Paulo: Duas Cidades, Editora 34, 2004. 480 p.

CANDIDO, Antonio. Jagunços mineiros de Cláudio a Guimarães Rosa. In: . Vários escritos. São Paulo: Livraria Duas Cidades, 1977. p. 133-160.

CANDIDO, Antonio. O homem dos avessos. In: Tese e antítese. 3. ed. São Paulo: Nacional, 1978. p. 119-139.

COSTA LIMA, Luiz. Regionalismo. In: COUTINHO, Afrânio (Org.) A literatura no Brasil. Rio: Editorial Sul Americana, 1970. v. 1, p. 279-326.

COUTINHO, Afrânio. O modernismo na ficção. In: COUTINHO, Afrânio (Org.) A literatura no Brasil. Rio: Editorial Sul Americana, 1970. v. 1, p. 203-227.

FINAZZI-AGRÒ, Ettore. Local, global, trivial. In: . Um lugar do tamanbo do mundo. Belo Horizonte: UFMG, 2001. cap. 3, p. 73-96.

FOUCAULT, Michel. Conferência 2. In: A verdade e as formas jurídicas. Trad. Roberto Cabral de Melo Machado, Eduardo Jardim Morais. Rio de Janeiro: Nau, 1996. p.29-52.

GALVÃO, Walnice Nogueira. As formas do falso. São Paulo: Perspectiva, 1972.

LAFETÁ, João Luiz. Estética e ideologia: o modernismo em 1930. Argumento: revista mensal de cultura, São Paulo, ano 1, n. 2, p. 19-32, [1972?].

LORENZ, Günter. Diálogo com Guimarães Rosa. In: COUTINHO, Eduardo F. Guimarães Rosa. Rio: Civilização Brasileira; Brasília, INL, 1983. p. 62-97. (Coleção Fortuna Crítica, 6).

OLIVEIRA, Luiz Cláudio Vieira de. Magma: as origens de Guimarães Rosa. Caligrama: Revista de Estudos Românicos da FALE/UFMG, Belo Horizonte, n. 10, p. 115-126, 2000.

PINTO, Milton José. Matraga: hora e vez das mitologias. Revista Vozes, Petrópolis, ano 65, v. 65 , n. 2, p. 39-48, mar. 1971. (2. ed. jan. 1973).

ROSA, João Guimarães. Partida do audaz navegante. In: Primeiras estórias. Rio de Janeiro: José Olympio, 1967. p. 114-123.

ROSA, João Guimarães. Grande Sertão: Veredas. 7. ed. Rio de Janeiro: José Olympio, 1970. $460 \mathrm{p}$.

STARLING, Heloísa. Lembranças do Brasil: teoria, política, história e ficção em Grande Sertão: Veredas. Rio de Janeiro: Revan, UCAM, IUPERJ, 1999. 192 p.

UTĖZA, Francis. Metafísica do Grande Sertão. Trad. José Carlos Garbuglio. São Paulo: Edusp, 1994. 459 p. 